\title{
Chronic Pain Following Lichtenstein Inguinal Hernia Repair: A Single Surgeon's Experience
}

\author{
Zaza Demetrashvili*,Tamar Metreveli, Ketevan Vibliani, Kakhi Khutsishvili, Eka Ekaladze and Levan \\ Akhalkatsi
}

Surgical Department, Tbilisi State Medical University, Georgia

Submission: June 13, 2016 ; Published: July 05, 2016

*Corresponding author:Zaza Demetrashvili, Surgical Department, Tbilisi State Medical University, Digomi Massivi block 6, building 23, apt 32, 0159 Tbilisi, Georgia, Tel: +995599217733; Fax: +995322392803; Email: zdemetr@yahoo.com

\begin{abstract}
Aim: The aim of our study was to determine the prevalence of chronic pain following Lichtenstein inguinal hernia repair and risk factors for pain development.

Methods: 347 patients with primary unilateral inguinal hernia underwent Lichtenstein repair. Some preoperative, perioperative and postoperative data were studied. Patients were examined for inguinal pain after one week following hernia repair (early postoperative pain), they were as well examined 1 and 3 months, 1 and 2 years following the surgery. Inguinal pain scores were measured on a Visual Analogue Scale (VAS), ranging from 0 (no pain) to 10 (worst imaginable pain). These pain scores were categorized as none (0), mild (1-3), moderate (4-7) and severe (8-10) pain.

Results: Information about 26 patients was lost during the observation. Subsequently 321 patients were examined during 2 years following the surgical intervention. One week later of the surgery 201 patients $(62.6 \%)$ were experiencing inguinal pain of different intensity, one month later pain was experienced by 102 patients (31.8\%), 3 months later- by 57 patients $(17.8 \%), 1$ year later by 34 patients $(10.6 \%)$ and 2 years later by 27 patients (8.4\%). Chronic postoperative inguinal pain (CPIP) development is correlated with following factors: preoperative pain (POP).
\end{abstract}

Abbreviations: VAS: Visual Analogue Scale; CPIP: Chronic Postoperative Inguinal Pain; POP: Pre-Operative Pain; ASA: American Society of Anesthesiologists; IASP: International Association for the Study of Pain; IASP: International Association for the Study of Pain; MPQ: McGill Pain Questionnaire; NPQ: Neuropathic Pain Questionnaire

\section{Introduction}

Inguinal hernia repair is one of the most frequently performed operations in general surgery. Annually, more than 20 million inguinal hernia repairs are conducted worldwide. Tensionfree mesh repair currently is the gold standard in inguinal hernia surgery [1]. Usage of prosthetic materials decreased the incidence of hernia recurrence, although chronic pain in the groin area after surgery is still a considerable problem - it worsens the level of patient's quality of life [2-4]. "Chronic postoperative inguinal pain" (CPIP) is now considered to be the most common and serious long-term problem after inguinal hernia repair. The incidence of CPIP varies from 6 to $52 \%$ of patients [2,5-7]. Significant pain (moderate and severe) affects daily life of 5-10\% [6,8-10]. The incidence of CPIP affecting normal daily activities has been estimated to be from 0.5 to $6.0 \%[5,11,12]$.

Lots of researches have been conducted for evaluation of CPIP after using different types of hernioplasty methods (open repair or laparoscopic). The results are heterogeneous. Numbers of recent papers have reported superiority of the laparoscopic method [10,13-15], however, there exists data indicating no prevalence of laparoscopic techniques [16-18]. The problem is most important in terms of primary unilateral inguinal hernias; Open mesh repair, especially Lichtenstein technique, is the first choice in the treatment of this disease $[1,19]$. The aim of this study was to prospectively determine the prevalence of CPIP following Lichtenstein inguinal hernia repair and identify the risk factors for CPIP development.

\section{Methods}

From January 2010 to December 2012 patients over 18 years of age who underwent elective surgery for unilateral primary inguinal hernia via the Lichtenstein technique were enrolled in the study. The patients were operated in the General Surgery Department of Kipshidze Central University Hospital. The inclusion criteria were a unilateral primary inguinal hernia 
requiring operative treatment and the patient's approval to participate in the study. The exclusion criteria were: Bilateral hernia, irreducible hernia, recurrent hernia, strangulated hernia, the patient's refusal to participate in the study. All patients were operated by one and the same skilled general surgeon with reasonable experience. The Lichtenstein hernioplasty was performed according to the original description of the technique [20]. The nerves in the inguinal canal were identified and preserved when possible. A monofilament polypropylene mesh (Prolene, Ethicon, Somerville, New Jersey) with size of $8 \times 12 \mathrm{~cm}$ was used. Polypropylene 2/0 monofilament suture material was used for mesh implantation.

Some preoperative data (sex, age, body mass index, occupation, tobacco use, site of hernia, risk groups by American Society of Anesthesiologists (ASA), comorbidities), perioperative data (type of hernia, method of anesthesia, duration of the operation) and postoperative data (pain, recurrence) were studied. Patients with ASA 4 and 5 were excluded from the study.

Pain registration was conducted several times: before the operation (preoperatively), seven days after the operation (early postoperative pain), 1 and 3 months, as well as 1 and 2 years after surgery. Inguinal pain scores were measured on a Visual Analogue Scale (VAS), ranging from 0 (no pain) to 10 (worst imaginable pain) [21]. These pain scores were categorized as none (0), mild (1-3), moderate (4-7) and severe (8-10) pain. After discharge from the hospital, all patients were examined after 1 week, 1 and 3 months, 1 and 2 years at the outpatient department by the surgeon or surgical resident. They were paying attention to the presence of pain in the inguinal region and hernia recurrence. The pain questionnaire included questions about intensity and localization of the pain, regarding pain at rest, when coughing, while climbing steps and during physical activity.

\section{Statistical Methods}

Statistical analysis was performed by SPSS 16.0 (SPSS Inc., Chicago, Il, USA). Comparison of continuous variables was performed by an independent samples t-test or MannWhitney $U$ test according to the normality of the variables. Categorical variables were evaluated by two-tailed Chi-square test or Fisher's exact test where appropriate. The threshold for statistical significance was set to $\mathrm{P}<0.05$.

\section{Results}

From January 2010 to December 2012, 439 patients underwent inguinal hernia repair via Lichtenstein technique. 347 among these patients were enrolled in the research group. All of these patients underwent the allocated operations. Information about 26 patients was lost during the time observation: among them- 17 refused to come for examination, 6 patients died during the observation period (the causes of death were all non-hernia surgery related), in 3 patients the development of a recurrent hernia took place. Subsequently 321 patients were examined during 2 years after surgical intervention. The data of this investigation is analyzed in this article (Figure1).

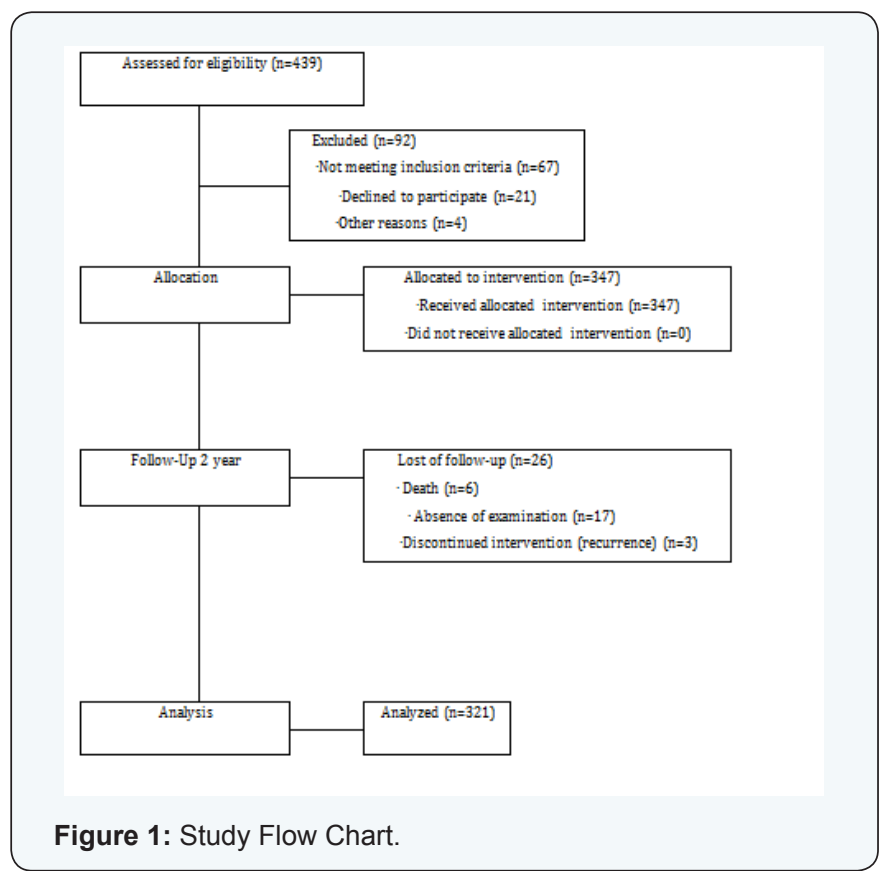

306 out of 321 patients were men. The patients' mean age was $54.7 \pm 15.2$ (range 18 - 88 years). Preoperative pain was designated in 168 patients (52.3\%). Baseline characteristics are summarized in (Table 1). 201 patients (62.6\%) complained of various intensity of pain in the inguinal area one week after the operation (early postoperative pain). 102 patients (31.8\%) denoted pain one month after the operation and 57 patients (17.8\%) - 3 months after surgical treatment. Chronic pain was marked in 34 patients $(10.6 \%)$ one year after the operation and in 27 patients $(8.4 \%)$ - two years after surgical treatment. Distribution of patients according to pain intensity (mild, moderate and severe) is shown in (Table 2). It is worth mentioning, that among 120 patients not having pain after seven days of surgical operation, only 2 patients $(1.67 \%)$ noted mild pain in one month and there was no complaint about pain in 3 months.

Table 1: Baseline characteristics $(n=321)$.

\begin{tabular}{|c|c|}
\hline Male & 306 \\
Female & 15 \\
\hline Mean age (years) & $54.7(17.2)$ \\
\hline BMI kg/m ${ }^{2}$ & $24.7(2.3)$ \\
\hline Hernia type & $96(29.9)$ \\
Direct & $201(62.6)$ \\
Indirect & $24(7.5)$ \\
Combined & \\
\hline
\end{tabular}




\section{Open Access Journal of Surgery}

\begin{tabular}{|c|c|}
\hline $\begin{array}{c}\text { Site of hernia } \\
\text { Right } \\
\text { Left }\end{array}$ & $\begin{array}{l}198 \\
123\end{array}$ \\
\hline Current smoker & 143 \\
\hline $\begin{array}{c}\text { Occupation } \\
\text { Light work } \\
\text { Physical work }\end{array}$ & $\begin{array}{l}143 \\
178\end{array}$ \\
\hline $\begin{array}{c}\text { Comorbidities } \\
\text { Cardiovascular } \\
\text { Respiratory system } \\
\text { Diabetes }\end{array}$ & $\begin{array}{l}59 \\
19 \\
16\end{array}$ \\
\hline $\begin{array}{l}\text { ASA risk group } \\
\qquad \begin{array}{c}1 \\
2 \\
3\end{array}\end{array}$ & $\begin{array}{r}99 \\
147 \\
75\end{array}$ \\
\hline $\begin{array}{l}\text { Mean operation } \\
\text { time (min) }\end{array}$ & $46.3(17.7)$ \\
\hline $\begin{array}{l}\text { Anesthesia } \\
\text { Local } \\
\text { Spinal } \\
\text { General }\end{array}$ & $\begin{array}{l}158(49.2) \\
80(24.9) \\
83(25.9)\end{array}$ \\
\hline $\begin{array}{l}\text { Preoperative pain } \\
\qquad \begin{array}{c}\text { No } \\
\text { Yes }\end{array}\end{array}$ & $\begin{array}{l}153(47.7) \\
168(52.3)\end{array}$ \\
\hline
\end{tabular}

Data are expressed as mean (SD) or absolute numbers of patients (\%).

BMI: Body mass index; ASA: American Society of Anesthesiologists

Table 2: Pain at follow-up $(n=321)$.

\begin{tabular}{|c|c|c|c|}
\hline & Total & Mild & Moderate+Severe \\
\hline 7 days & $201(62.6)$ & $147(45.8)$ & $54(16.8)$ \\
\hline 1 month & $102(31.8)$ & $74(23.1)$ & $28(8.7)$ \\
\hline 3 month & $57(17.8)$ & $40(12.5)$ & $17(5.3)$ \\
\hline 1 year & $34(10.6)$ & $25(7.8)$ & $9(2.8)$ \\
\hline 2 year & $27(8.4)$ & $20(6.2)$ & $7(2.2)$ \\
\hline
\end{tabular}

Data are expressed as absolute number of patients (\%).

According to our data, preoperative pain and CPIP development are correlate. Among 168 patients, who had preoperative pain, CPIP was marked in 27 patients $(16.1 \%)$. On the other hand, CPIP was characteristic for only 7 patients (4.6\%) out of 153 that had not complained of preoperative pain $(\mathrm{P}<0.001)$. Two year after operation among 168 patients, who had preoperative pain, CPIP was marked in 23 patients $(13.7 \%)$. CPIP was characteristic for only 4 patients $(2.6 \%)$ out of 153 that had not complained of preoperative pain $(\mathrm{P}<0.001)$ (Table 3$)$.
Table 3: Correlation between preoperative pain and chronic pain.

\begin{tabular}{|c|c|c|c|}
\hline Characteristics & $\begin{array}{c}\text { Preoperative no } \\
\text { pain } \\
\mathbf{n = 1 5 3}\end{array}$ & $\begin{array}{c}\text { Preoperative } \\
\text { pain } \\
\mathbf{n = 1 6 8}\end{array}$ & $\begin{array}{c}\mathbf{P} \\
\text { Value }\end{array}$ \\
\hline $\begin{array}{c}\text { 1 month } \\
\text { Pain }\end{array}$ & $36(23.5)$ & $66(39.3)$ & 0.0027 \\
\hline $\begin{array}{c}3 \text { month } \\
\text { Pain }\end{array}$ & $18(11.8)$ & $39(23.2)$ & 0.0084 \\
\hline $\begin{array}{c}\text { 1 year } \\
\text { Pain }\end{array}$ & $7(4.6)$ & $27(16.1)$ & $<0.001$ \\
\hline $\begin{array}{c}2 \text { year } \\
\text { Pain }\end{array}$ & $4(2.6)$ & $23(13.7)$ & $<0.001$ \\
\hline
\end{tabular}

Data are expressed as absolute number of patients (\%).

A younger age also correlates with the development of CPIP. One year after the operation CPIP developed in 15 persons $(17.4 \%)$ out of 86 patients aging less than 45 years, and 19 $(8.1 \%)$ out of 235 patients who were older than 45 years $(\mathrm{P}=0.04)$. At the same time, there were no differences between these groups in the terms of the intensity of pain (VAS) (Table 4).

Table 4: Pain and visual analogue scale (VAS) for age groups at follow-up.

\begin{tabular}{|c|c|c|c|}
\hline Characteristics & $\begin{array}{c}\text { Age }<45 \text { year } \\
n=86\end{array}$ & Age $>45$ year & $\begin{array}{c}\mathbf{P} \\
\text { Value }\end{array}$ \\
\hline $\begin{array}{c}7 \text { days } \\
\text { Pain } \\
\text { VAS }\end{array}$ & $\begin{array}{c}51(59.3) \\
4.1 \pm 2.8\end{array}$ & $\begin{array}{c}150(63.8) \\
3.7 \pm 2.3\end{array}$ & $\begin{array}{l}0.52 \\
0.19\end{array}$ \\
\hline $\begin{array}{c}1 \text { month } \\
\text { Pain } \\
\text { VAS }\end{array}$ & $\begin{array}{c}31(36.0) \\
3.5 \pm 2.0\end{array}$ & $\begin{array}{c}71(30.2) \\
3.2 \pm 1.8\end{array}$ & $\begin{array}{l}0.34 \\
0.20\end{array}$ \\
\hline $\begin{array}{c}3 \text { month } \\
\text { Pain } \\
\text { VAS }\end{array}$ & $\begin{array}{c}20(23.3) \\
2.5 \pm 1.4\end{array}$ & $\begin{array}{c}37(15.7) \\
2.4 \pm 1.3\end{array}$ & $\begin{array}{l}0.14 \\
0.53\end{array}$ \\
\hline $\begin{array}{c}1 \text { year } \\
\text { Pain } \\
\text { VAS }\end{array}$ & $\begin{array}{c}15(17.4) \\
2.0 \pm 1.2\end{array}$ & $\begin{array}{l}19(8.1) \\
1.8 \pm 1.1\end{array}$ & $\begin{array}{l}0.02 \\
0.16\end{array}$ \\
\hline $\begin{array}{c}2 \text { year } \\
\text { Pain } \\
\text { VAS }\end{array}$ & $\begin{array}{l}12(14.0) \\
1.5 \pm 1.0\end{array}$ & $\begin{array}{l}15(6.4) \\
1.4 \pm 0.9\end{array}$ & $\begin{array}{l}0.04 \\
0.39\end{array}$ \\
\hline
\end{tabular}

VAS: Visual Analogue Scale

Data are expressed as absolute numbers of patients (\%) or as mean and SD.

Our research indicates correlation between early postoperative pain (moderate and severe) and CPIP. CPIP more frequently has occurred in patients with moderate and severe postoperative pain in 3 months, as well as one and two years after surgery compared to patients who marked early 
postoperative pain with mild intensity $(\mathrm{P}=0.0325, \mathrm{P}=0.0024$, $\mathrm{P}<0.001$, respectively) (Table 5).

Table 5: Correlation between early postoperative pain (7 day) and chronic pain.

\begin{tabular}{|c|c|c|c|}
\hline Characteristic & $\begin{array}{c}\text { Early } \\
\text { postoperative } \\
\text { mild } \\
\text { pain } \mathbf{n = 1 4 7}\end{array}$ & $\begin{array}{c}\text { Early } \\
\text { postoperative } \\
\text { moderate } \\
\text { and severe pain } \\
\mathbf{n = 5 4}\end{array}$ & Palue \\
\hline 3 month Pain & $34(23.1)$ & $21(38.9)$ & 0.0325 \\
\hline 1 year Pain & $17(11.6)$ & $17(31.5)$ & 0.0024 \\
\hline 2 year Pain & $12(8.2)$ & $15(27.8)$ & $<0.001$ \\
\hline
\end{tabular}

Data are expressed as absolute number of patients (\%).

Table 6: Proportion of patients with chronic pain after 1 year.

\begin{tabular}{|c|c|c|c|}
\hline Parameters & No pain & Pain & $P$ Value \\
\hline \multicolumn{4}{|c|}{ Patient parameters } \\
\hline $\begin{array}{c}\text { Occupation } \\
\text { Light work } \\
\text { Physical work }\end{array}$ & $\begin{array}{l}127 \\
160\end{array}$ & $\begin{array}{l}16 \\
18\end{array}$ & 0.86 \\
\hline $\begin{array}{c}\mathrm{BMI} \mathrm{kg} / \mathrm{m}^{2} \\
\quad<25 \\
\quad \geq 25\end{array}$ & $\begin{array}{l}127 \\
160\end{array}$ & $\begin{array}{l}13 \\
21\end{array}$ & 0.59 \\
\hline $\begin{array}{c}\text { Smoker } \\
\text { No smoker }\end{array}$ & $\begin{array}{l}123 \\
164\end{array}$ & $\begin{array}{l}20 \\
14\end{array}$ & 0.10 \\
\hline \multicolumn{4}{|c|}{ Hernia parameters } \\
\hline $\begin{array}{c}\text { Hernia side } \\
\text { Right } \\
\text { Left }\end{array}$ & $\begin{array}{l}175 \\
112\end{array}$ & $\begin{array}{l}23 \\
11\end{array}$ & 0.58 \\
\hline $\begin{array}{l}\text { Hernia type } \\
\text { Direct } \\
\text { Indirect + } \\
\text { combined }\end{array}$ & $\begin{array}{c}88 \\
199\end{array}$ & $\begin{array}{c}8 \\
26\end{array}$ & 0.44 \\
\hline \multicolumn{4}{|c|}{ Surgery parameters } \\
\hline $\begin{array}{l}\text { Operation time, } \\
\text { min } \\
<45 \\
\geq 45\end{array}$ & $\begin{array}{l}141 \\
146\end{array}$ & $\begin{array}{l}16 \\
18\end{array}$ & 0.86 \\
\hline $\begin{array}{l}\text { Anesthesia type } \\
\text { Local } \\
\text { Spinal } \\
\text { General }\end{array}$ & $\begin{array}{c}145 \\
70 \\
72\end{array}$ & $\begin{array}{l}13 \\
10 \\
11\end{array}$ & 0.21 \\
\hline
\end{tabular}

BMI: Body Mass Index

Data are expressed as absolute number of patients.
Development of CPIP was not related to the following factors: occupation status $(\mathrm{P}=0.86), \mathrm{BMI}(\mathrm{P}=0.59)$, tobacco use $(\mathrm{P}=0.10)$, hernia side $(\mathrm{P}=0.58)$, hernia type $(\mathrm{P}=0.44)$, operation time $(\mathrm{P}=0.86)$, anesthesia type $(\mathrm{P}=0.21)$ (Table 6).

\section{Discussion}

Usage of meshes in the treatment of inguinal hernia has sharply decreased the recurrence of hernia, on the other hand, problem of CPIP has been originated. The CPIP frequency variability is within $6-52 \%$ and remarkably deteriorates quality of life $[2,3,5-7,10-12,22,23]$. The differences between chronic pain frequencies after inguinal hernioplasty is caused by differences in the definition, measurement and timing of assessment $[5,7,9,24]$. The International Association for the Study of Pain (IASP) defines chronic pain as a pain lasting for more than 3 months after the injury [25]. Several scientific articles are using this definition in terms of post-herniorrhaphy pain, but as it is based on nonsurgical chronic pain, this elucidation is incomplete.

Recently the following definition was accepted: postherniorraphy pain is the pain that arises as a direct consequence of a nerve lesion or a disease affecting the somatosensory system in patients who did not have groin pain before the original operation or, if they did, the post-operative pain was different from the pre-operative pain. Chronic pain that is present from 3 months after surgery and which lasts beyond 6 months after surgery [5].

We investigated CPIP after Lichtenstein hernioplasty of primary unilateral inguinal hernia. Our results revealed that $17.8 \%$ out of all patients operated with Lichtenstein technique had pain after 3 months, $10.6 \%$ patients - after 1 year and $8.4 \%$ - after 2 years. Our data showed the correlation between the factors supporting development of CPIP. Preoperative pain, younger age $(<45$ year), moderate or severe early postoperative pain are the risk factors for the development of CPIP. The same are considered as risk -factors for chronic pain development in European Hernia Society guidelines on the treatment of inguinal hernia in adult patients [1,19].

We found preoperative pain to be significant predictor for the development of CPIP after Lichtenstein hernia repair. Our results coincide with other scientists' data $[6,7,12,13,23,26,27]$. Our findings indicated the importance of moderate and severe pain during early postoperative period for CPIP development. This correlation is also approved by different scientific works $[6,7,13,23$,$] . One remarkable fact was revealed in our research:$ no chronic pain was mentioned 1 and 2 years after surgery in the patients who had no complaint on early postoperative pain. The reasons of association between CPIP on the one hand and preoperative and early severe postoperative pain - on the other - are not known. Although, several mechanisms have been proposed, including sensitization of nociceptors in the 
surgical field, perioperative nerve damage, central sensitization, postoperative ectopic activity of injured primary afferents, and structural changes in the central nervous system [7].

Different studies shows, that several prophylactic methods must be applied to reduce CPIP. That method includes:

a. During inguinal hernioplasty all three inguinal nerves have to be identified and protected from damage.

b. Preventive multimodal analgesia and anesthesia should be given high priority. Preventive measures such as infiltration of local anesthetic, peri- and postoperative gabapentinoids or ketamine treatment, might minimize the inflammatory cascade, decrease central sensitization, and prevent development of severe chronic pain $[5,7,9]$.

According to our findings young age $(<45$ year) is a considerable risk for CPIP development. This data is in accordance with several investigations [6,7,12,13,26-28]. Although there are different scientific opinions Donati et al. [29], indicating no correlation between age and chronic pain. Our results did not show the difference between age groups in terms of pain intensity (VAS). This fact indicates that age is the riskfactor of CPIP development and it does not determine intensity of pain.

Several scientists state that women are under the risk of CPIP $[6,7]$. We have not investigated the correlation between gender and CPIP as there were 306 men and only 15 women involved in our research. There was no statistically reliable relation between CPIP and factors, like BMI, occupation, tobacco use, hernia side, hernia type, operation time, and anesthesia type. There are several investigations indicating the same findings $[6,7,27]$, but there also exist different opinions: Nienhuijs et al. [22] confirm that heavy physical work is the risk-factor of chronic pain, Verstraete et al. [30] indicate that CPIP is more frequently developed after general and regional anesthesia, compared to local anesthesia; the findings of Poobalan et al. [26] reveals connection between chronic pain and BMI, though not pronounced. The fact is explained by the difficulty of identification of ilioinguinal nerve in obese patients, and at the same time association between chronic pain and BMI is considered as a coincidence by the authors.

According to our findings the frequency of chronic pain is diminished as time passes: $17.8 \%$ of the patients marked pain 3 months after operation, and only $10.6 \%$ and $8.4 \%$ - after 1 and 2 years, accordingly. We think that additional research is needed to confirm this fact, even though there are findings in scientific literature indicating the idea $[15,19,22,31]$.

Limitations for our study are:

i. For pain measurement we used VAS and the pain questionnaire included questions about intensity and localization of the pain, regarding pain at rest, when coughing, while climbing steps and during physical activity.
For pain evaluation we did not used detailed forms such as McGill Pain Questionnaire (MPQ), Neuropathic Pain Questionnaire (NPQ) and for evaluation quality of life SF-36 (36-Item Short Form Health Survey).

ii. For CPIP development we did not studied genetic factors.

\section{Conclusion}

In conclusion, several factors including preoperative pain, young age and early postoperative pain (moderate and severe) are the risk factors for chronic postopertive pain for patients operated by Lichtenstein technique. Frequency of the chronic pain diminishes in the course of time. Identification of patients with risk factors may enable improved acute postoperative pain analgesia which might reduce CPIP. Future randomized studies are necessary to test this hypothesis. Finally, we emphasize that prophylactic methods to reduce CPIP should have the highest priority.

\section{Acknowledgment}

We are thankful to Dr. George Kamkamidze for the help to carried out the statistical analysis.

\section{Author Contribution}

Demetrashvili Z participated in the design and coordination of the study, collected the data, analyzed the data, carried out the statistical analysis and wrote the manuscript; Metreveli T, Vibliani $\mathrm{K}$, and Khutsishvili K developed the literature search, collected the data and assisted in writing up. Ekaladze E and Akhalkatsi L assisted in writing up. All authors read and approved the final manuscript.

\section{References}

1. Simons MP, Aufenacker T, Bay-Nielsen M, Bouillot JL, Campanelli G, et al. (2009) European hernia society guidelines on the treatment of inguinal hernia in adult patients. Hernia 13(4): 343-403.

2. Palmquist E, Larsson K, Anell A, Hjalmarsson C (2013) Prospective study of pain, quality of life and economic impact of open inguinal hernia repair. Br J Surg 100(11): 1483-1488.

3. Kehlet H, Bay-Nielsen M, Danish Hernia Database Collaboration (2008) Nationwide quality improvement of groin hernia from the Danish Hernia database of 87840 patients from 1998 to 2005. Hernia 12(1): $1-7$.

4. Massaron S, Bona S, Fumagalli U, Valente P, Rosati R (2008) Long-term sequele after 1311 primary inguinal hernia repairs. Hernia 12(1): 5763.

5. Alferi S, Amid PK, Campanelli G, Izard G, Kehlet H, et al. (2011) International guidelines for prevention and management of postoperative chronic pain following inguinal hernia surgery. Hernia 15(3): 239-249.

6. Aasvang E, Kehlet H (2005) Chronic postoperative pain: the case of inguinal herniorrhaphy. Br J Anesth 95(1): 69-76.

7. Bjurstrom MF, Nicol AL, Amid PK, Chen DC (2014) Pain control following inguinal herniorrhaphy: current perspectives. J Pain Res 29(7): 277-290. 
8. Hakeem A, Shanmugam V (2011) Inguinodinia following Lichtenstein tension-free hernia repair: a review. World J Gastroenterol 17(14): 1791-1796.

9. Lange JF, Kaufmann R, Wijsmuller AR, Pierie JP, Ploeg RJ, et al. (2015) An International consensus algorithm for management of chronic postoperative inguinal pain. Hernia 19(1): 33-43.

10. Nienhuijs S, Staal E, Strobbe L, Rosman C, Groenewoud H, et al. (2007) Chronic pain after mesh repair of inguinal hernia: a systematic review. Am J Surg 194(3): 394-400.

11. Kehlet H (2008) Chronic pain after groin hernia repair. Br J Surg 95(2): 135-136.

12. Franneby U, Sandblom G, Nordin P, Nyren O, Gunnarsson U (2006) Risk factors for long-term pain after hernia surgery. Ann Surg 244(2): 212 219.

13. Singh AN, Bansal VK, Misra Mc, Kumar S, Rajeshwari S, et al. (2012) Testicular functions, chronic pain, and quality of life after laparoscopic and open mesh repair of inguinal hernia: a prospective randomized controlled trial. Surg Endosc 26(5): 1304-1317.

14. Cavazzola LT, Rosen MJ (2013) Laparoscopic versus open inguinal hernia repair. Surg Clin North Am 93(5): 1269-1279.

15. Eklund A, Montgomery A, Bergkvist L, Rudberg C; Swedish Multicentre Trial of inguinal hernia repair by laparoscopy (SMIL) study group (2010) Chronic pain 5 years after randomized comparison of laparoscopic and Lichtenstein inguinal hernia repair. Br J Surg 97(4) 600-608.

16. Wang WJ, Chen JZ, Fang Q, Li JF, Jin PF, et al. (2013) Comparison of the effects of laparoscopic hernia repair and Lichtenstein tension-free hernia repair. J Laparoendosc Adv Surg Tech A 23(4): 301-305.

17. Eklund A, Rudberg C, Leijonmarck CE, Rasmussen I, Spangen L, Wickbom G, Wingren U, Montgomery A (2007) Recurrent inguinal hernia: randomized multicenter trial comparing laparoscopic and Lichtenstein repair. Surg Endosc 21(4): 634-640.

18. Cheong KX, LoHY, Neo JX, Appasamy V, Chiu MT (2014) Inguinal hernia repair: are the results from a general hospital comparable to those from dedicated hernia centres? Singapore Med J 55(4): 191-197.

19. Miserez M, Peeters E, Aufenacker T, Bouillot JL, Campanelli G, et al (2014) Update with level 1 studies of the European Hernia Society guidelines on the treatment of inguinal hernia in adult patients. Hernia 18(2): 151-163.
20. Lichtenstein IL, Schulman AG, Amid PK, Montllor MM (1989) The tension-free hernioplasty. Am J Surg 157(2): 188-193.

21. McCarthy M Jr, Chang CH, Pickard AS, Giobbie-Hurder A, Price DD, et al. (2005) Visual analog scales for assessing surgical pain. J Am Coll Surg 201(2): 245-252.

22. Nienhuijs SW, Rosman C (2015) Long-term outcome after randomizing prolene hernia system, mesh plug repair and Lichtenstein for inguinal hernia repair. Hernia 19(1): 77-81.

23. Aasvang EK, Gmaehle E, Hansen JB, Gmaehle B, Forman JL, et al. (2010) Predictive risk factors for persistent postherniotomy pain. Anesthesiology 112(4): 957-969.

24. Van Hanswijck de Jonge P, Lloyd A, Horsfall L, Tan R, O’Dwyer PJ (2008) The measurement of chronic pain and health-related quality of life following inguinal hernia repair: a review of literature. Hernia 12(6): 561-569.

25. Classification of chronic pain (1986) Description of chronic pain syndromes and definitions of pain terms. Prepared by International Association for the study of pain Subcommitte on taxonomy. Pain Suppl 3: S1-S226

26. Poobalan AS, Bruce J, King PM, Chambers WA, Krukowski ZH, et al. (2001) Chronic pain and quality of life following open inguinal hernia repair. Br J Surg 88(8): 1122-1126.

27. Dickinson KJ, Thomas M, Fawole AS, Lyndon PJ, White CM (2008) Predicting chronic post-operative pain following laparoscopic inguinal hernia repair. Hernia 12(6): 597-601.

28. Langeveld HR, Kitsie P, Smedinga H, Eker H, Van't Reit M, et al. (2015) Prognostic value of age for chronic postoperative inguinal pain. Hernia 19(4): 549-555.

29. Donati M, Brancato G, Giglio A, Biondi A, Basile F, et al. (2013) Incidence of pain after inguinal hernia repair in the elderly. A retrospective historical cohort evaluation of 18-years' experience with about 3000 patients. BMC Surgery 13(2): S19.

30. Verstraete L, Because N, Swannet H, Ceelen W, Duchateau L, et al. (2015) Long term outcome after Lichtenstein hernia repair using general, locoregional and local anaesthesia. Acta Chir Belg 115(2): 136-141.

31. van Veen RN, Wijsmuller AR, Wrijland WW, Hop Wc, Lange JF, et al. (2007) Randomized clinical trial of mesh versus non-mesh primary inguinal hernia repair: long-term chronic pain at 10 years. Surgery 142(5): 695-698. 